\title{
SINCRONISMO DE DISPOSITIVOS PARA O GEORREFERENCIAMENTO DE IMAGENS DIGITAIS
}

\author{
Device Synchronization for Digital Images Georeferencing \\ THIAGO TIEDTKE DOS REIS \\ PAULO DE OLIVEIRA CAMARGO \\ ANTONIO MARIA GARCIA TOMMASELLI \\ Faculdade de Ciências e Tecnologia - Unesp \\ PPGCC - Programa de Pós-Graduação em Ciências Cartográficas \\ Rua Roberto Simonsen, 305, CEP 19060-900, Presidente Prudente, São Paulo \\ tiedtke@gmail.com; \{paulo, tomaseli\}@fct.unesp.br
}

\begin{abstract}
RESUMO
Sensores de posição e orientação podem ser adquiridos e integrados com um custo relativamente baixo para aplicações em mapeamento. A utilização de câmaras digitais de pequeno e médio formato em sistemas de aquisição de imagens aéreas, proporciona vantagens sobre sistemas fotogramétricos convencionais, como: redução de custo, dimensões e peso. Este trabalho teve como objetivo a implementação e avaliação de hardware e software para permitir o sincronismo entre receptores GPS e câmaras digitais de modo a fornecer diretamente as coordenadas do centro perspectivo. O sincronismo foi realizado com o uso do sistema operacional Linux, juntamente com o software NTP, responsável por sincronizar o relógio do computador com uma referência de tempo externa. A validação foi realizada comparando-se diretamente os instantes registrados pelo sistema comercial SPAN-CPT e a técnica proposta neste trabalho. Além disto, os Centros Perspectivos (CPs) determinados pelas técnicas implementadas foram usados em experimentos com fototriangulação de um bloco de imagens, possibilitando a análise de discrepâncias nos pontos de verificação. $\mathrm{O}$ resultado do sincronismo apresentou discrepâncias da ordem de $0,15 \mathrm{~m}$ em relação ao sistema comercial, implicando na determinação das coordenadas dos CPs com qualidade compatível com a aplicação da técnica desenvolvida em projetos de mapeamento.

Palavras-chave: Sincronismo; Fototriangulação Apoiada por GPS; Georreferenciamento Direto; Orientação Integrada de Sensores.
\end{abstract}




\section{ABSTRACT}

Currently, position and orientation sensors can be acquired and integrated with affordable costs for mapping applications. In this context, small and medium format digital cameras can be included as a part of aerial image acquisition system with advantages when compared to conventional photogrammetric systems, due to its low cost, size, weight and handling ease. This work aims at the implementation and experimental assessment of hardware and software components for synchronization of a GPS receiver and a digital camera to directly measure and provide the perspective center coordinates. Synchronization was based on Linux operational system, and NTP software, used to synchronize computer time with an external reference time. The validation of the implemented system was perfomed by comparing directly the events recorded in a commercial navigation system (SPANCPT) and from the proposed technique. Furthermore, the PC coordinates determined by these techniques were used in an aerial triangulation, enabling the analysis of discrepancies in the checkpoints. The result of the synchronization showed discrepancies rounding $0.15 \mathrm{~m}$ with respect to the commercial system, resulting in the determination of the PC coordinates with quality compatible with its application in mapping projects.

Keywords: Synchronization; GPS Based Aerial Triangulation; Direct Georeferencing; Integrated Sensor Orientation.

\section{INTRODUÇÃO}

As câmaras digitais de médio formato vêm sendo consideradas como alternativa efetiva para serviços de mapeamento, devido ao baixo custo, se comparadas a sistemas fotogramétricos de aquisição de imagens digitais de grande formato. Atualmente, há uma grande disponibilidade de modelos de câmaras digitais no mercado, dentre as quais se destacam as de médio e grande formato. Estas câmaras possuem estabilidade interna aceitável e grande capacidade de armazenamento de dados, o que as tornam economicamente atrativas para atividades de aerolevantamento e mapeamento (HABIB e MORGAN, 2003), desde que sejam observados os procedimentos compatíveis com as técnicas fotogramétricas.

Somente o uso de câmaras digitais, entretanto, não implica em aumento da eficiência no mapeamento. Dependendo da dimensão da área a ser mapeada, tanto a operação manual de aquisição (acionamento), como o processamento em sistemas fotogramétricos digitais demanda muito tempo e cuidados (processos de orientação e medição de pontos de passagem), o que pode tornar antieconômico o uso deste tipo de câmaras em grandes projetos.

Combinando-se adequadamente câmaras digitais, sensores de posição e orientação, dispositivos de aquisição, sincronismo e disparo, pode-se obter imagens digitais diretamente orientadas, com custos relativamente baixos, se comparados aos 
sistemas existentes no mercado. A acurácia da orientação direta das imagens será proporcional à precisão dos sensores e interfaces utilizadas.

A proposta deste trabalho é a implementação e avaliação de técnicas de sincronismo de dados para o posicionamento direto de imagens coletadas por câmaras digitais, com o emprego de receptores GPS (Global Positioning System). Foram estudadas diversas configurações de coleta de dados, a partir de interfaces eletrônicas, algoritmos computacionais, câmaras digitais, receptores GPS e sensores inerciais, resultando numa classificação da precisão da orientação direta para as configurações apresentadas, bem como no desenvolvimento físico de algumas das alternativas estudadas e sua avaliação experimental em situações reais.

A utilização do sistema proposto (Linux e receptor de simples frequência) permite a montagem de um sistema de custo inferior aos sistemas comerciais, mas ainda com exatidão compatível com as aplicações de mapeamento.

Este trabalho fez uso dos equipamentos do sistema SAAPI (Sistema Aerotransportado de Aquisição e Pós-processamento de Imagens digitais) que é formado por uma plataforma de coleta de imagens e dados auxiliares, composta por sensores ópticos com múltiplas configurações, sensores de posição/orientação, uma unidade de controle e alimentação, computador de navegação, controle e armazenamento. Este sistema também prevê algoritmos de calibração e processamento de imagens e dados. O detalhamento completo do sistema SAAPI pode ser encontrado em Ruy (2008) e uma revisão sobre sistemas similares em Petrie (2010).

\section{ORIENTAÇÃO DIRETA DE IMAGENS DIGITAIS E ESCALA DE TEMPO}

A orientação exterior de uma imagem é definida por seis parâmetros, sendo três rotações e três coordenadas da origem do referencial fotogramétrico em relação ao referencial do espaço objeto. A fototriangulação em bloco por feixes de raios é o processo fotogramétrico que tem por objetivo determinar estes Parâmetros de Orientação Exterior (POE), em conjunto com as coordenadas de pontos no espaço objeto e suas respectivas precisões, a partir de observações feitas em fotografias ou imagens digitais e de valores aproximados para os parâmetros. Para tanto, a fototriangulação utiliza pontos de apoio no terreno, os quais possuem coordenadas bem determinadas, para calcular indiretamente, por meio de modelos matemáticos que relacionam um ponto na imagem a um ponto no terreno, os POE de uma imagem (CRAMER et al., 1999). Porém, esta abordagem tem custos e tempo de processamento altos, que encarecem o projeto fotogramétrico.

Além das coordenadas de pontos de apoio, devem ser conhecidos a priori os Parâmetros de Orientação Interior (POI), que definem a geometria interna da câmara (distância focal, ponto principal e parâmetros que modelam as distorções das lentes e outros erros sistemáticos). Estes parâmetros são determinados através 
de processos de calibração ou estimados no processo de fototriangulação (calibração em serviço).

Os POE também podem ser determinados diretamente por meio de sensores de posição (GPS e/ou GNSS) e atitude (Giroscópios e acelerômetros), processo conhecido como orientação direta de sensores (JACOBSEN, 2003), ou georreferenciamento direto (SKALOUD, 1999). A rigor, o georreferenciamento preciso de uma imagem e, portanto, de todos os pixels que a compõem, deveria incluir, além da posição e orientação, o processo de ortorretificação. Caso contrário, os pixels ainda estariam afetados pelo deslocamento devido ao relevo. Entretanto, o termo georreferenciamento direto, tem sido usado como sinônimo de orientação direta na maioria dos artigos recentes.

O uso do GPS isoladamente para a determinação das coordenadas dos centros perspectivos pode reduzir, embora não elimine a necessidade de pontos de apoio no projeto fotogramétrico, uma vez que não se dispõe de dados de atitude do sensor. Com isto, a integração entre os sensores GPS e inerciais (GPS/INS) tornou-se uma ferramenta para a determinação de forma direta da orientação exterior das imagens.

O processo de orientação direta pode ser seguido pela fototriangulação por feixes de raios, ajustando-se simultaneamente as informações fornecidas pelos sensores de orientação direta, as observações fotogramétricas e as coordenadas de pontos de apoio, o que permite a correção de erros sistemáticos residuais. Pode-se, além disto, estimar in situ e com maior confiabilidade os Parâmetros de Orientação Interior. Este processo é chamado de orientação integrada de sensores (JACOBSEN, 2003).

Os modelos matemáticos para estes processos são baseados nas equações de colinearidade, acrescidas de parâmetros adicionais, sendo o conjunto de parâmetros estimado pelo método dos mínimos quadrados com injunções. Estes modelos são suficientemente conhecidos, recomendando-se consultar Andrade (1998) e Mikhail et al. (2001).

Alguns destes parâmetros adicionais podem incluídos no ajustamento em bloco especificamente para absorver erros decorrentes do posicionamento GPS, como a perda de ciclos e erros na sincronização com a câmara. O modelo mais comum inclui três translações (shift) e três fatores de escala (drift) dependentes do tempo, podendo ser aplicados por faixa ou por bloco (MIKHAIL et al., 2001, p. 129).

Mesmo com a inclusão destes parâmetros é importante a correta sincronização entre os dispositivos, o que requer a manutenção rigorosa da base do tempo. Os erros de sincronização causam a deterioração da precisão do georreferenciamento direto e possuem várias causas, como: atraso interno do hardaware, atraso na transmissão dos dados, atraso na marcação de tempo e erro na leitura do relógio do computador (El SHEIMY, 1996, p. 106). 
Desta forma, trabalhando com registro de eventos associados a uma base de tempo única, é possível obter as informações de posição sem a necessidade de fazer modificações ou intrusões no hardware original dos equipamentos.

Normalmente o tempo pode ser associado à ocorrência de dois eventos em instantes distintos. Sendo assim, a diferença entre os dois instantes define a quantidade ou intervalo de tempo. Essa quantidade representada pela ocorrência de dois eventos distintos é medida por um relógio.

Com a evolução dos sistemas de manutenção de tempo, diversas escalas de tempo surgiram, podendo ser definidas por convenções utilizadas para medir e representar esta grandeza. Estas escalas devem ser estáveis, homogêneas e não fornecer informação ambígua. Todas estas escalas são baseadas em observações uniformes e repetitivas de fenômenos astronômicos e físicos. O intervalo entre dois fenômenos consecutivos define a escala de medida em uma escala de tempo particular (SEEBER, 2003).

O GPS tem sua escala de tempo própria, denominada Tempo GPS (GPS Time). Esta escala difere do UTC (Universal Time Coordinated) por alguns segundos inteiros. Tanto o UTC quanto o Tempo GPS tem sua origem na época 6 de janeiro de 1980, sendo incrementado por saltos de segundos (SEEBER, 2003).

A coordenação de eventos em uma base de tempo única é conhecida como sincronismo. Em sistemas e dispositivos eletrônicos, dos mais simples aos mais avançados, geralmente se torna necessário o uso de bases de tempos controladas e confiáveis.

Em ambientes computacionais, um software muito difundido é o servidor de tempo NTP (Network Time Protocol - Protocolo de tempos para Rede) para a finalidade de sincronização. Normalmente usam-se servidores de tempo com a intenção de manter os horários de computadores ou redes de computadores corretamente ajustados (sincronizados), em aplicações que necessitam de registro de informações com grande precisão na escala do tempo (MILLS, 1990). O servidor de tempo realiza a sincronização obtendo a hora de uma referência de tempo confiável, e distribui essa informação aos usuários usando uma rede de computadores. O NTP pode, por exemplo, usar referências de tempo externas como relógios atômicos, sinais de sincronismo de receptores GPS (através da saída 1 PPS - One Pulse per Second).

\section{INTEGRAÇÃO DE DISPOSITIVOS E TÉCNICAS DE SINCRONIZAÇ̃̃o}

Os detalhes das técnicas propostas e implementadas são mostrados na Tabela 1, sendo que as diferenças básicas são função do tipo de receptor GPS (responsáveis pela coleta dos dados de posicionamento e pelo sinal de sincronismo), pelas interfaces utilizadas na comunicação e sincronismo de dados.

Com base no conhecimento prévio dos sistemas envolvidos, pode-se supor que a técnica 1 apresenta um custo reduzido, mas também menor acurácia, quando comparada à técnica 2, o que a torna útil em aplicações temáticas, como a 
elaboração de mosaicos para agricultura ou como plataforma de posicionamento de Veículos Aéreos Não Triupulados (VANTs).

Tabela 1 - Configurações propostas.

\begin{tabular}{|c|c|c|}
\hline \multirow{2}{*}{$\begin{array}{c}\text { Componentes do } \\
\text { sistema }\end{array}$} & \multicolumn{2}{|c|}{ Técnicas de sincronização e coleta implementadas } \\
\hline & 1 & 2 \\
\hline GPS & $\begin{array}{l}\text { - Simples frequência com } \\
\text { saída PPS } \\
\text { - Taxa de coleta de dados } \\
\text { brutos: } 1 \mathrm{~Hz}\end{array}$ & $\begin{array}{l}\text { - Dupla frequência com } \\
\text { saída PPS e registro de } \\
\text { eventos no GPS } \\
\text { - Taxa de coleta de dados } \\
\text { brutos: } 5 \mathrm{~Hz}\end{array}$ \\
\hline $\begin{array}{c}\text { Técnica de } \\
\text { sincronismo de } \\
\text { tempo }\end{array}$ & $\begin{array}{l}\text { - NTP } \\
\text { - NMEA e PPS via serial }\end{array}$ & $\begin{array}{l}\text { - NTP } \\
\text { - NMEA e PPS via serial }\end{array}$ \\
\hline CPU e Hardware & $\begin{array}{l}\text { - Desktop ou Notebook } \\
\text { - Porta Serial } \\
\text { - Porta Paralela } \\
\end{array}$ & $\begin{array}{l}\text { - Desktop ou Notebook } \\
\text { - Porta serial } \\
\text { - Porta paralela }\end{array}$ \\
\hline $\begin{array}{c}\text { Sistema } \\
\text { operacional }\end{array}$ & - Linux & - Linux \\
\hline Registro de evento & - Porta Serial & $\begin{array}{l}\text { - Porta Serial } \\
\text { - GPS }\end{array}$ \\
\hline $\begin{array}{c}\text { Erro de } \\
\text { Sincronismo }\end{array}$ & 0,001 a $0,01 \mathrm{~s}$ & $<0,001 \mathrm{~s}$ \\
\hline $\begin{array}{c}\text { Erro Posicional } \\
\text { Esperado em } \\
\text { função do erro de } \\
\text { sincronismo* } \\
\end{array}$ & 0,06 a $0,6 \mathrm{~m}$ & -Menor que $0,06 \mathrm{~m}$ \\
\hline Observações & $\begin{array}{l}\text { - Pós-processamento dos } \\
\text { dados GPS } \\
\text { - Erro inserido pelo evento } \\
\text { de disparo da câmara } \\
(\sim 0,001 \mathrm{~s})\end{array}$ & $\begin{array}{l}\text { - Pós-processamento dos } \\
\text { dados GPS } \\
\text { - Erro inserido pelo evento } \\
\text { de disparo da câmara } \\
(\sim 0,001 \mathrm{~s})\end{array}$ \\
\hline $\begin{array}{c}\text { Tipo de } \\
\text { Processamento dos } \\
\text { dados GPS }\end{array}$ & $\begin{array}{l}\text { - Processamento Relativo - Es } \\
\text { PPTE (RBMC) - Aprox. } 113 \\
\text { LINS (Rede GNSS SP) - Apr } \\
\text { OURI (Rede GNSS SP) - Ap } \\
\text { - Efemérides Precisas e corre } \\
\text { (IGS); } \\
\text { - Correção das velocidades da } \\
\text { - Interpolação Linear das coo }\end{array}$ & $\begin{array}{l}\text { tações de Referência: } \\
\text { km da área do voo; } \\
\text { ox. } 130 \mathrm{~km} \text { da área do voo; } \\
\text { rox. } 67 \mathrm{~km} \text { da área do voo; } \\
\text { ções do relógio dos satélites } \\
\text { s estações pelo VelInter; } \\
\text { denadas dos CPs. }\end{array}$ \\
\hline
\end{tabular}

* velocidade aproximada da aeronave: $60 \mathrm{~m} / \mathrm{s}$ 
A técnica 2, que apresenta melhor acurácia, embora a um custo maior, devido aos sensores que o compõem (receptor GPS de dupla frequência), será considerada como a referência para fins de comparações de instantes de aquisição e posições dos CPs. Este sistema está originalmente integrado ao sistema SAAPI, que é composto, ainda, por uma Unidade de Medida Inercial integrada ao GPS (Sistema SPAN/CPT da Novatel), câmara digital e dispositivos eletrônicos de acionamento e controle.

Para permitir a execução e testes com as técnicas propostas, foram necessários desenvolvimentos de hardware que possibilitaram o compartilhamento de alguns dispositivos já existentes no sistema SAAPI (antena GPS e evento de disparo da câmara). A Figura 1 mostra os principais dispositivos utilizados neste trabalho, bem como algumas conexões existentes com o sistema SAAPI e os componentes da técnica 1.

Além da ligação física apresentada, foram necessárias várias implementações de algoritmos para registro dos eventos de disparo, por meio da porta serial do computador, bem como para armazenamento dos dados brutos do GPS, para o pósprocessamento e, posteriormente, a interpolação das coordenadas dos instantes de disparos (CP) em função dos instantes registrados.

Uma parte destas implementações diz respeito à necessidade de manter todos os registros de eventos em uma escala de tempo única (tempo GPS). Desta forma, ao se comparar os instantes dos disparos vindos do sistema SAAPI (instantes dos eventos registrados no SPAN-CPT), e as marcas de tempo registradas pelo computador de sincronismo (pulso de disparo recebido da câmara - Figura 1), não será necessária mais nenhuma conversão, visto que já possuem uma mesma origem (às 0 hora de 06 de janeiro de 1980).

Figura 1 - Adaptação do sistema SAAPI para funcionar paralelamente à técnica de sincronismo proposta neste trabalho.

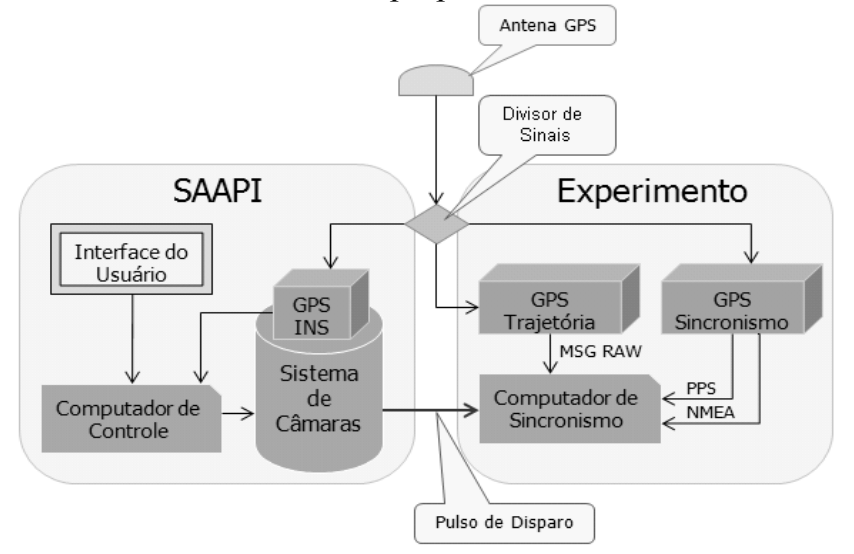

Bol. Ciênc. Geod., sec. Artigos, Curitiba, v. 17, nº 3, p.317-339, jul-set, 2011. 
É importante ressaltar a importância do software NTP juntamente com o sistema operacional Linux para a tarefa de sincronizar os tempos entre o Receptor GPS e o computador que registra os eventos de disparos. Outros sistemas operacionais também possuem softwares complementares que permitem a sincronização precisa como o NMEA Time para o SO Windows (VISUALGPS, LLC, 2011). À época de início do projeto, entretanto, testes preliminares com este SO produziram resultados inferiores aos proporcionados pelo Linux, pois neste as interrupções respondem mais rapidamente, pela possibilidade de recompilar o núcleo com as características desejadas.

Foram necessárias modificações no sistema operacional utilizado, com o intuito de possibilitar a recepção de uma referência de tempo externa para os demais dispositivos conectados ao sistema, como será detalhado na seção 3.1.

\subsection{Modificações no Sistema Operacional Linux}

Com o intuito de reduzir o custo com aquisição de hardware e software proprietário para as operações de sincronismo/registro de eventos, foi adotada uma solução similar à descrita em Wis et al. (2004), optando-se por usar os recursos de hardware existentes no PC (porta serial), e do sistema operacional livre Linux, em sua distribuição Debian. O código fonte do Linux pode ser recompilado, modificado e usado para qualquer finalidade, inclusive comercial, desde que mantidas as referências e atribuições aos autores de cada software (GPLV3, 2009).

Para que o sistema operacional Linux responda aos eventos de disparos das câmaras, bem como aos pulsos vindos do receptor GPS usado como referência de tempo, foram necessárias modificações em seu núcleo, tornando-o apto reconhecer e a responder a esses eventos. Existe um erro de sincronismo devido a atrasos e interrupções de hardware no processo de marcação do evento, porém em testes de laboratório, verificou-se que este erro é da ordem de um micro segundo (REIS, 2009).

O LinuxPPS é uma API (Application Programming Interface) aplicada ao núcleo do Linux, responsável por receber os pulsos de sincronismo da saída PPS do receptor usado como referência de tempo e enviá-lo ao NTP para a manutenção do tempo. O mesmo processo é usado para "capturar" os eventos de disparos das câmaras durante o voo. Esta API foi parcialmente incorporada ao código fonte do Linux desde 2009 (LINUSPPS, 2011).

\subsection{Sincronização entre GPS e o Computador}

Para o sincronismo entre o GPS e o computador foi usado o software NTP (versão 4.2.4 p2) juntamente com o núcleo do Linux modificado, para ter suporte ao sinal PPS vindo do receptor GPS. O LinuxPPS adiciona ao núcleo do Linux a capacidade de reconhecer mudanças de estados do nível lógico de pinos específicos do hardware serial e paralelo existentes em um computador. A leitura dos pulsos 
temporizados (PPS), vindos do receptor GPS, é feita por meio de interrupções no pino 1 (DCD) de uma porta serial do computador, sendo transferida a uma estrutura interna do sistema operacional para tratamento pelo NTP. O receptor GPS envia o sinal PPS, no instante da mudança de segundo em seu relógio interno. Após o envio do pulso, são feitos os processamentos e cálculos internos para o posicionamento absoluto.

Além do sinal PPS, é necessária também a informação referente ao instante a que esse pulso se refere, mesmo que essa informação não tenha precisão quanto similar ao sinal PPS. Isto é obtido com as mensagens NMEA. O receptor GPS envia mensagens pela porta serial para o computador de controle. A sincronização é feita de forma automática pelo NTP logo que mensagens válidas no formato NMEA sejam recebidas pela porta serial do computador. Após um ajuste inicial do relógio do computador, com uso de poucas amostras de mensagens NMEA (sentença \$GPGGA) o NTP passa a considerar em seus cálculos estatísticos os pulsos recebidos pelo pino 1 da porta serial (REIS, 2009).

\subsection{Coleta do Instante de Disparo}

Devido à impossibilidade de modificar o hardware original da câmara, foi utilizada outra técnica para detectar e registrar o momento de disparo. Normalmente, câmaras fotográficas profissionais ou semi-profissionais possuem saídas para flash externo que são muito bem sincronizadas com o obturador do sistema de lentes.

Desta forma, a solução adotada para obter o pulso de disparo da câmara foi monitorar o conector de flash, e registrar transições de estados que ocorrem, usando o mesmo advento da sincronização do relógio do computador com o GPS (LinuxPPS monitorando o pino 1 de uma porta serial, por exemplo). Assim, no instante em que o obturador da câmara se abre, registrando a imagem, este instante é marcado e referenciado à escala de tempo GPS.

\section{EXPERIMENTOS}

Nesta seção serão descritos os experimentos realizados para testar as técnicas propostas. Algumas informações e características relevantes a respeito do voo realizado são descritas a seguir:

Data do voo: 31/03/2009, das 8 às 10 horas local (11 às 13 horas do tempo GPS, aproximadamente);

Área do voo: Cidade de Assis/SP - Altitude aproximada da Região: 450 m; Altitude aproximada do voo: $1500 \mathrm{~m}$;

Intervalo entre as tomadas de 4 segundos, de forma a garantir $60 \%$ de sobreposição longitudinal entre as imagens;

Velocidade média da aeronave de $220 \mathrm{~km} / \mathrm{h}$;

Equipamentos embarcados no voo (Tabela 1): 
Um computador com sistema operacional Linux, para registro dos pulsos de disparo da câmara via porta serial (técnica 1), interligado a um receptor GPS SuperStar II de simples frequência para sincronismo (com a saída PPS, para fins de sincronização) e outro (também um receptor GPS SuperStar II, de simples frequência) para coleta das observáveis (dados) para pós-processamento;

Componentes do sistema SAAPI na aeronave, usando a técnica 2 de sincronismo;

Os receptores GPS usados compartilharam a mesma antena já existente na aeronave por meio de um divisor de sinais, garantindo que as medidas das observáveis GPS fossem realizadas na mesma posição;

Câmara digital Hasselblad H3D II, com 39 MegaPixels, distância focal nominal de $50 \mathrm{~mm}$, sensor com dimensões de 49 × $36,7 \mathrm{~mm}$, com 7216 colunas, 5412 linhas e pixel quadrado com tamanho de $6,8 \mu \mathrm{m}$

Para os experimentos foram coletadas 60 imagens com a câmara Hasselblad, com GSD (Ground Sample Distante) de aproximadamente $15 \mathrm{~cm}$ na posição nadir, como segue:

Faixa 1: Sentido Oeste->Leste -22 imagens;

Faixa 2: Sentido Leste->Oeste - 23 imagens;

Faixa 3: Sentido Sul->Norte -7 imagens;

Faixa 4: Sentido Norte->Sul -8 imagens.

\subsection{Determinação do Vetor Posição da Antena GPS no Referencial Fotogramétrico (Lever Arm)}

Para garantir que as coordenadas associadas aos eventos de disparo e a trajetória do receptor GPS estejam referidas ao sistema fotogramétrico, foi necessário a determinação do vetor entre o CP da câmara e o CF (Centro de fase) da antena GPS.

Tabela 2 - Vetores que relacionam os diversos sensores embarcados (Lever Arm).

\begin{tabular}{c|c|c|c}
\hline Offset & $\Delta \mathbf{X}(\mathbf{m})$ & $\Delta \mathbf{Y}(\mathbf{m})$ & $\Delta \mathbf{Z}(\mathbf{m})$ \\
\hline IMU -> Antena & $0,023 \pm 0,015$ & $-0,076 \pm 0,015$ & $0,716 \pm 0,015$ \\
\hline CAM -> IMU & $0,0 \pm 0,015$ & $0,0 \pm 0,015$ & $-0,316 \pm 0,015$ \\
\hline
\end{tabular}

Utilizando um fio de prumo e uma trena, foram medidas as três componentes do vetor que conecta a origem do sistema Fotogramétrico (ponto nodal anterior) da câmara ao CF da antena GPS. Estas medidas foram realizadas com uma precisão média de $0,015 \mathrm{~m}$. Os valores dos vetores que relacionam os diversos sensores utilizados e respectivas precisões são apresentados na Tabela 2.

Uma variação angular de 3o (rolagem ou arfagem da aeronave) produz um deslocamento na posição da antena em relação ao ponto nodal anterior (origem do referencial fotogramétrico) de aproximadamente $5 \mathrm{~cm}$, o que permite considerá-lo desprezível para o caso estudado, pois a exatidão do posicionamento relativo 
cinemático é da ordem de $15 \mathrm{~cm}$. Embora a precisão nominal sugerida pelo fabricante seja da ordem de $2 \mathrm{~cm}$, sabe-se que esta estimativa é otimista, tendo sido considerado o valor de $15 \mathrm{~cm}$ como mais realista (CRAMER et al., 2000).

O software GrafNav, da Novatel-WayPoint, usado para o pós-processamento, aceita os valores de Lever Arm pré determinados como parâmetros de entrada, e, automaticamente realiza a redução das coordenadas do centro de fase da antena GPS para o centro perspectivo da câmara. Existe a possibilidade de inserir também os ângulos de rotação de cada imagem, desde que previamente conhecidos, no software GrafNav para a correção destes efeitos, mas esta opção não foi utilizada neste trabalho.

\subsection{Determinação dos Instantes dos Disparos da Câmara em Relação ao Tempo GPS}

Durante a execução do voo, o NTP registra em arquivo e mantém as estatísticas atualizadas a respeito do erro de sincronismo entre o pulso do pino PPS (relógio do GPS) e o relógio do computador. Estes registros estatísticos feitos pelo NTP são usados para compensar diferenças entre os dois relógios ao longo do tempo e gravados no arquivo chamando loopstats (NTP, 2008).

No mesmo voo do experimento, outro arquivo de dados é gerado a partir das marcas de eventos do receptor SPAN/CPT, contendo informações dos instantes de disparo da câmara (técnica 2). Este arquivo será usado para comparação com os instantes de disparo registrados pela técnica 1.

Figura 2 - Discrepâncias entre instantes de disparos registrados pelas técnicas 1 e 2.

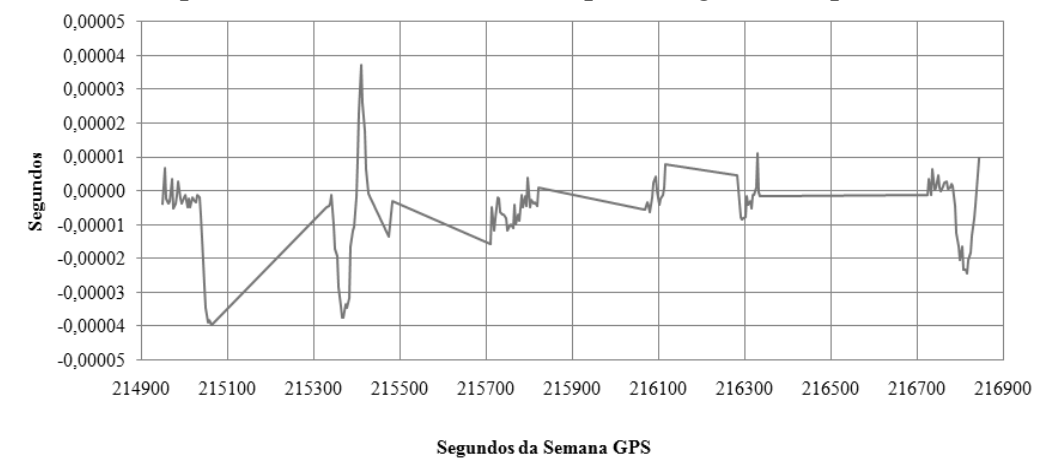

A Figura 2 exibe as discrepâncias entre os dois registros de eventos (técnicas 1 e 2).

Pode-se observar que, mesmo com alguns picos na Figura 2, as discrepâncias tornam-se muito pequenas, com valores máximos em módulo próximos de 0,00004 s $(40 \mu \mathrm{s})$, quando corrigidos de valores registrados durante as amostragens 
realizadas pelo NTP, para ajuste do relógio do computador (após 16,67 minutos de sincronismo (REIS, 2009).

\subsection{Processamento dos Dados GPS}

No processamento pela técnica 1 de sincronismo, foram obtidos valores médios de desvio padrão $(1 \sigma)$ de $0,10 \mathrm{~m}$ e $0,20 \mathrm{~m}$ para as componentes horizontal e vertical, respectivamente. Para a técnica 2, os valores de desvio padrão obtidos foram de $0,035 \mathrm{~m}$ (componente horizontal) e $0,070 \mathrm{~m}$ (componente vertical). A Figura 3 apresenta as discrepâncias entre as coordenadas obtidas pelas duas técnicas.

Figura 3 - Discrepâncias entre coordenadas dos CPs obtidas pelas técnicas 1 e 2.

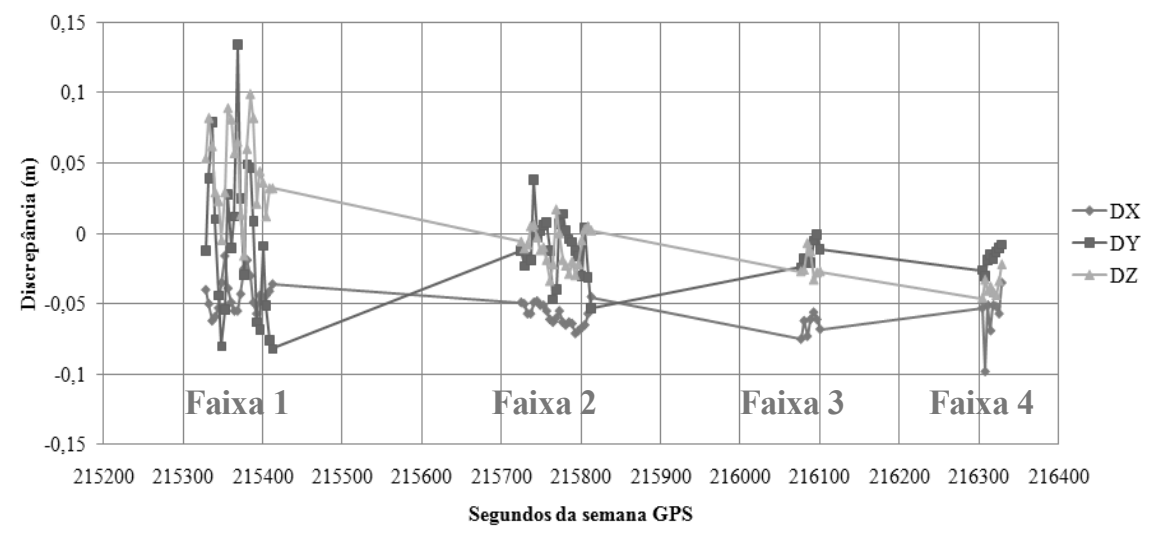

Observa-se que na primeira faixa, as discrepâncias nas três componentes possuem uma magnitude maior que nas demais. Isto pode estar relacionado ao sincronismo realizado pelo NTP, que necessita de um tempo mínimo para iniciar a convergência (16,67 minutos) (NTP, 2008), ocasionando um deslocamento significativo entre o relógio do computador e o relógio do GPS L1, usado como referência de tempo. Deve-se levar em consideração que receptores GPS possuem internamente algoritmos para manutenção e estabilização do tempo, o que acarreta a melhora no posicionamento com o passar do tempo, da mesma forma que ocorre com o sincronismo realizado pelo NTP. No caso de um receptor GPS, ocorrem diferenças de sincronismo entre os relógios dos satélites e o relógio interno do receptor.

Ainda de acordo com a Figura 3, especificamente nas faixas 2, 3 e 4, percebese um comportamento de convergência dos valores de discrepâncias para um valor máximo próximo a $0,10 \mathrm{~m}$, a partir da segunda faixa, o que confirma o que foi comentado no parágrafo anterior. 
É importante ressaltar que os valores obtidos podem ser considerados como muito bons, já que se trata de posicionamento relativo com linha de base de aproximadamente $70 \mathrm{~km}$, com coleta em modo cinemático e uso de um receptor de simples frequência (Técnica 1).

\subsection{Testes de Fototriangulação com Injunções nas Coordenadas dos CPs}

Foram realizados alguns processamentos de fototriangulação convencional, com pontos de apoio medidos em campo, para fins de comparação com as coordenadas dos CPs obtidos pelo método proposto.

A fototriangulação teve os seguintes procedimentos comuns:

-adoção de um sistema de referência cartesiano local, para evitar distorções de escala causadas pelo uso de projeções, como por exemplo, a UTM (JACOBSEN, 2003); Desta forma, todos os pontos de apoio, verificação e cada posição da trajetória estão referenciadas a uma origem arbitrária definida próximo à área do voo;

-fototriangulação por feixes de raios, com medição automática dos pontos fotogramétricos;

-calibração em serviço para obtenção de parâmetros de orientação interior (POI) da câmara;

-reamostragem da imagem para correção das distorções das lentes.

Neste trabalho optou-se pelo uso da autocalibração (calibração em serviço) da câmara a serem usados na fototriangulação de todo o bloco de imagens. Para isto alguns procedimentos foram considerados durante a aquisição (WOLF e DEWIT, 2000):

Determinação com grande precisão das coordenadas dos CPs de cada imagem (técnica 2). Os desvios padrão obtidos do processamento de dados GPS (relativo cinemático) foram menores que $0,15 \mathrm{~m}$; de OI.

Execução de faixas cruzadas, de forma a reduzir correlações entre parâmetros

Foi selecionado um pequeno bloco contendo 22 imagens em 3 faixas cruzadas, com 9 pontos de apoio distribuídos por esta área. As coordenadas dos CPs obtidas pela técnica 2 foram usadas como injunções para a autocalibração. Os pontos de passagem (Figura 4) foram medidos automaticamente pelo software LPS (Leica Photogrammetric Suite) com precisão subpixel, os quais, antes de serem usados na autocalibração, foram analisados em um processo em um controle de qualidade geométrico interno, visando remover pontos com resíduos elevados ou pontos medidos de forma equivocada pelo LPS. O bloco para autocalibração teve 469 pontos de passagens medidos nas imagens, gerando 3488 equações. Os valores de EMQ dos resíduos da autocalibração foram de 0,198 m para X, 0,077 $\mathrm{m}$ para $\mathrm{Y}$ e $0,050 \mathrm{~m}$ para $\mathrm{Z}$. 
A Figura 4 mostra a configuração do bloco usada na autocalibração e distribuição dos pontos de apoio. O resultado da autocalibração realizada é apresentado na Tabela 3.

Figura 4 - Bloco de imagens usadas para autocalibração da câmara, com a disposição dos pontos de apoio e dos pontos de passagem.

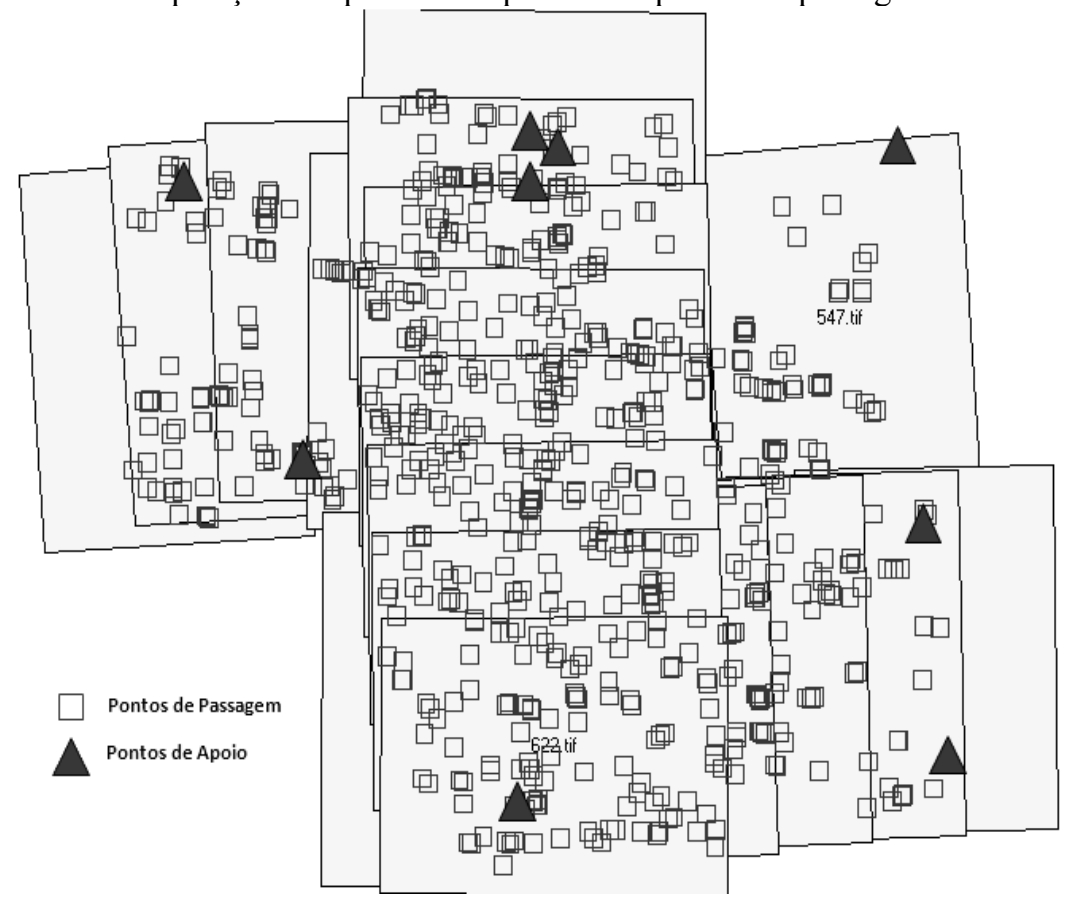

Tabela 3 - Parâmetros de OI estimados na autocalibração.

\begin{tabular}{|c|c|c|c|c|c|c|c|}
\hline $\begin{array}{c}\mathbf{f} \\
(\mathbf{m m})\end{array}$ & $\begin{array}{c}\mathbf{x 0} \\
(\mathrm{mm})\end{array}$ & $\begin{array}{c}\mathbf{y 0} \\
(\mathbf{m m})\end{array}$ & $\begin{array}{c}\mathrm{k} 1 \\
\left(\mathrm{~mm}^{-2}\right)\end{array}$ & $\begin{array}{c}\mathrm{k} 2 \\
\left(\mathrm{~mm}^{-4}\right)\end{array}$ & $\begin{array}{c}\mathrm{k3} \\
\left(\mathrm{mm}^{-6}\right)\end{array}$ & $\begin{array}{c}\mathbf{p 1} \\
\left(\mathrm{mm}^{-1}\right)\end{array}$ & $\begin{array}{c}\mathrm{p2} \\
\left(\mathrm{mm}^{-1}\right)\end{array}$ \\
\hline $\begin{array}{l}50,181 \\
\pm 0,003\end{array}$ & $\begin{array}{l}-0,168 \\
\pm 0,004\end{array}$ & $\begin{array}{l}0,248 \\
\pm 0,003\end{array}$ & $\begin{array}{l}-2,86 \times 10^{-5} \\
\pm 2,55 \times 10^{-7}\end{array}$ & $\begin{array}{l}1,34 \times 10^{-8} \\
\pm 8,02 \times 10^{-10}\end{array}$ & $\begin{array}{l}3,15 \times 10^{-12} \\
\pm 7,59 \times 10^{-13}\end{array}$ & $\begin{array}{l}2,23 \times 10^{-6} \\
\pm 5,92 \times 10^{-7}\end{array}$ & $\begin{array}{l}1,35 \times 10^{-7} \\
\pm 5,5 \times 10^{-7}\end{array}$ \\
\hline
\end{tabular}

Utilizando os parâmetros de OI estimados na autocalibração, realizou-se a reamostragem das imagens originais para correção das distorções das lentes e da posição do ponto principal, com o software LensDcorrec, desenvolvido pelo grupo de pesquisa em Fotogrametria da Unesp, específico para esta finalidade. Este software usa como entrada, parâmetros de OI (para a reamostragem das imagens deste experimento, usaram-se os seguintes parâmetros: f, x0, y0, k1, k2, p1, p2). 
Como esta reamostragem das imagens elimina as distorções das lentes e translada a imagem para posicionar o ponto principal no centro geométrico, pode-se usar o modelo de correções de distorções de lentes do LPS com valores nulos, sendo necessário somente o valor da distância focal (f ) estimada na autocalibração. Isto foi necessário porque experimentos preliminares mostraram que os modelos de distorções implementados na versão do LPS utilizada (versão 9.2) não se comportaram da forma esperada em projetos envolvendo câmaras com lentes com valores altos de distorção.

\subsection{Fototriangulação do Bloco Experimental}

Foi realizada uma fototriangulação no sistema LPS, para verificar as discrepâncias entre os valores das posições dos CPs, determinados por uma fototriangulação clássica e os valores obtidos com as técnicas de sincronismo 1 e 2 . O projeto fotogramétrico utilizou 24 pontos de apoio, 7 pontos de verificação e 844 pontos fotogramétricos, determinados automaticamente pelo LPS. Os parâmetros de OI foram considerados fixos, uma vez que foram determinados anteriormente na etapa de autocalibração. Às coordenadas dos pontos medidos nas imagens foram atribuídas precisões de 0,5 pixel. As coordenadas dos CPs foram informadas com desvios-padrão de $30 \mathrm{~m}$, na forma de injunção relativa, e os ângulos de rotação foram considerados livres $(\sigma=1800)$.

Figura 5 - Configuração do bloco de e disposição dos pontos de apoio.

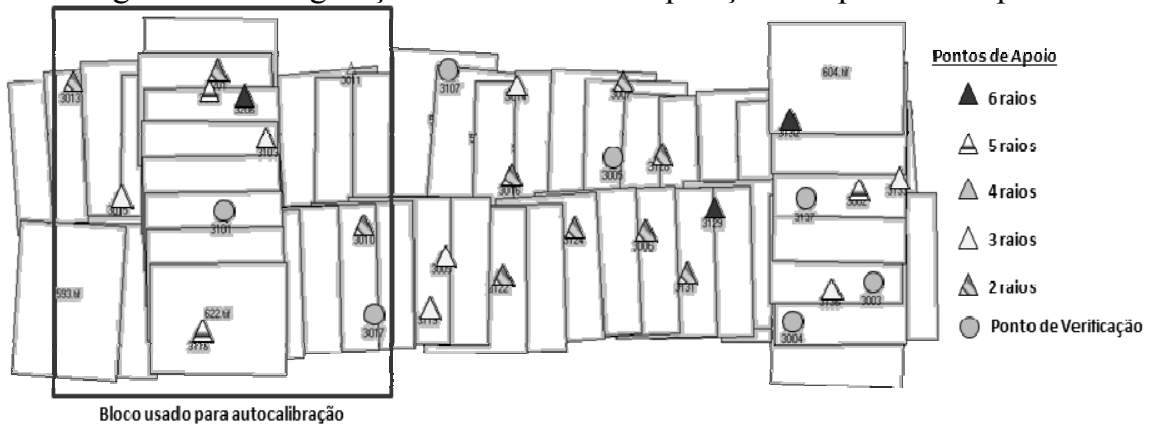

Os pontos de apoio foram medidos com receptores GPS de dupla frequência no modo estático e processados em rede com 3 estações da RBMC (Rede Brasileira de Monitoramento Contínuo, estações PPTE, OURI, LINS) obtendo-se precisão centimétrica, tendo sido vinculados no ajustamento em bloco com uma precisão de $15 \mathrm{~cm}$.

A Figura 5 mostra a configuração do bloco, com a distribuição dos pontos de apoio e verificação utilizados, e o número de raios fotogramétricos que interceptam 
cada ponto. O resultado da fototriangulação é exibido na Tabela 4, com valores dos resíduos e do EMQ nos pontos de verificação e de apoio usados no bloco.

Tabela 4 - Resíduos nos pontos de apoio e verificação para o experimento com a configuração apresentada na Figura 5.

\begin{tabular}{l|c|c|c|c|c|c}
\cline { 2 - 7 } & \multicolumn{3}{c|}{ Pontos de apoio } & \multicolumn{3}{c}{ Pontos de Verificação } \\
\hline \multicolumn{1}{c|}{ Ponto } & dX (m) & $\mathbf{d Y}(\mathbf{m})$ & $\mathbf{d Z}(\mathbf{m})$ & $\mathbf{d X}(\mathbf{m})$ & $\mathbf{d Y}(\mathbf{m})$ & $\mathbf{d Z}(\mathbf{m})$ \\
\hline Média & 0,000 & 0,000 & 0,000 & $-0,094$ & 0,016 & 0,050 \\
\hline $\begin{array}{l}\text { Desvio } \\
\text { Padrão }\end{array}$ & 0,114 & 0,082 & 0,034 & 0,162 & 0,120 & 0,163 \\
\hline EMQ & 0,112 & 0,081 & 0,033 & 0,177 & 0,113 & 0,159 \\
\hline
\end{tabular}

Pela análise da Tabela 4 verifica-se que os resultados estão compatíveis com o esperado, sendo que as discrepâncias nos pontos de verificação apresentam estatísticas similares às dos pontos de apoio. O EMQ nos pontos de verificação é da ordem de 1 GSD $(15 \mathrm{~cm})$, ou seja, da mesma ordem de magnitude do erro de medida dos pontos de apoio na imagem, indicando que todos os erros sistemáticos foram eliminados de modo adequado.

Após a fototriangulação as coordenadas dos CPs calculadas pelo LPS foram comparadas com suas correspondentes obtidas com as técnicas 1 e 2, sendo as discrepâncias apresentadas na Tabela 5. As Figuras 6 e 7 mostram os gráficos destas discrepâncias para a técnica 1 e a técnica 2 , respectivamente.

Tabela 5 - Discrepâncias entre as coordenadas dos CPs: Fototriangulação x técnica 1 e 2.

\begin{tabular}{l|c|c|c|c|c|c}
\hline & \multicolumn{3}{|c|}{ Fototriangulação x Técnica 1 } & \multicolumn{2}{c}{ Fototriangulação x Técnica 2 } \\
\cline { 2 - 7 } & DX & DY & DZ & DX & DY & DZ \\
\hline Média (m) & 0,0385 & 0,0180 & 0,0140 & 0,0317 & 0,0144 & 0,0141 \\
\hline EMQ (m) & 0,1963 & 0,1343 & 0,1207 & 0,1781 & 0,1201 & 0,1186 \\
\hline EMQ (GSD) & 1,3 & 0,9 & 0,8 & 1,2 & 0,8 & 0,8 \\
\hline
\end{tabular}

Observa-se na Tabela 5 uma pequena redução nas discrepâncias entre os CPs obtidos pela técnica 2 e os CPs obtidos por fototriangulação, o que pode estar relacionado com a maior acurácia obtida pelo receptor de dupla frequência.

Erros referentes ao sincronismo poderiam ser absorvidos usando-se parâmetros de shift e drift (MIKHAIL et al., 2001) que existem em alguns softwares de fototriangulação, porém o LPS, na versão utilizada, não permite a estimação destes parâmetros.

Como era esperado, as Figuras 6 e 7 são similares e as discrepâncias nas coordenadas obtidas pelas duas técnicas não ultrapassaram $0,15 \mathrm{~m}$. Observando as Figuras 6 e 7, bem como a Tabela 5, pode-se concluir que as técnicas 1 e 2 são 
compatíveis entre si, já que as coordenadas obtidas por uma fototriangulação clássica e as coordenadas dos CPs determinados pelas técnicas de orientação direta apresentadas, divergem, no máximo, em 0,6 m.

Figura 6 - Discrepâncias entre as coordenadas dos CPs obtidas por fototriangulação e a técnica 1 .

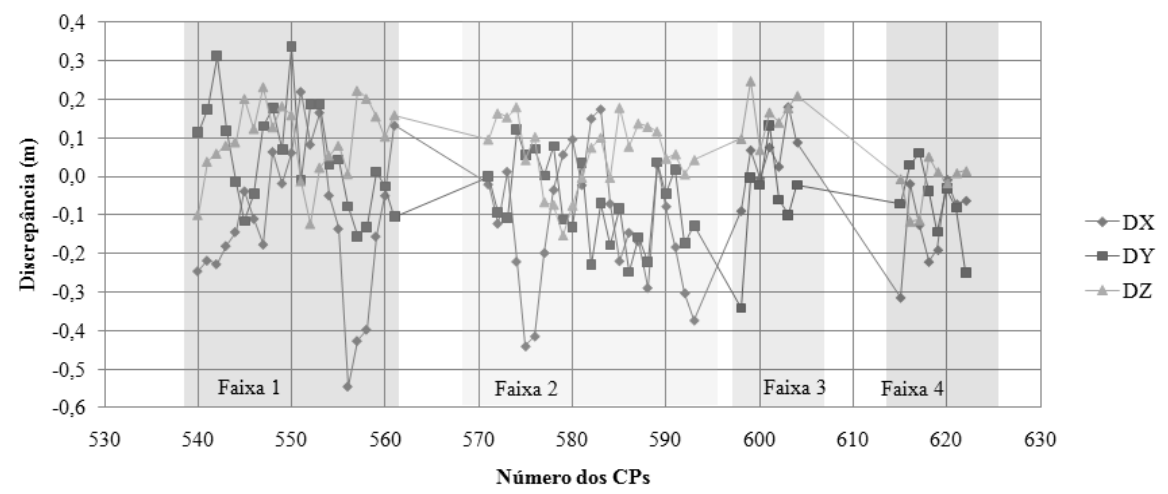

Figura 7 - Discrepâncias entre as coordenadas dos CPs obtidas por fototriangulação e a técnica 2 .

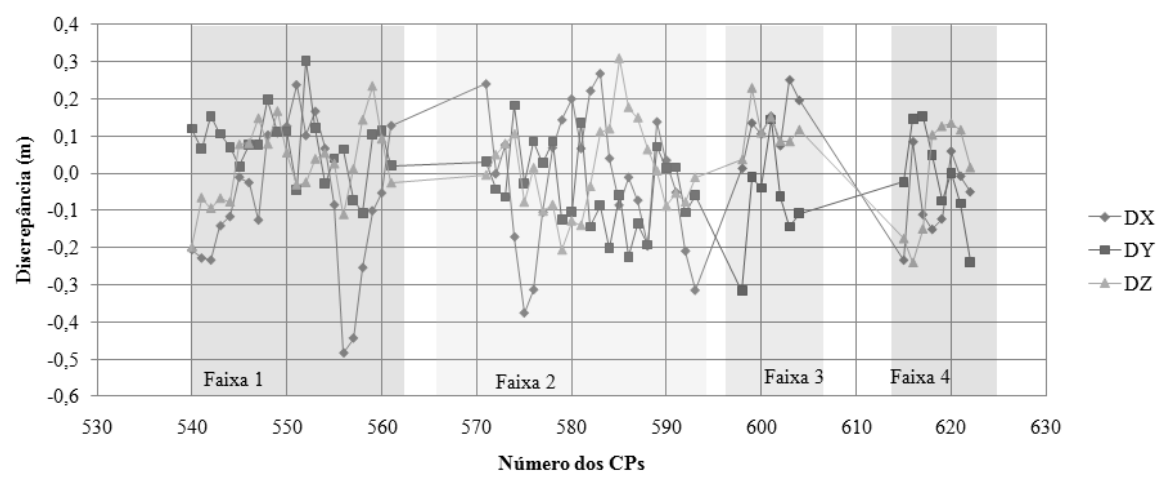

\subsection{Fototriangulação com Injunções nas Coordenadas dos CPs Obtidas pela} Técnica 1

Foi realizado outro conjunto de experimentos de fototriangulação usando os CPs determinados pela técnica 1 como injunções. Somente a técnica 1 foi utilizada neste caso, por se tratar do desenvolvimento propriamente dito.

Foram utilizadas as configurações no software LPS para a execução da fototriangulação similares às usadas no experimento anterior (seção 4.5), exceto pelo desvio padrão nas coordenadas dos CPs, agora fixados com desvios-padrão de 
0,20 $\mathrm{m}$ para as três componentes e os parâmetros de OI foram considerados fixos nestes experimentos. Estes valores para os desvios padrão dos CPs, englobam incertezas do processamento relativo cinemático, erros de medidas do vetor (Lever Arm) entre antena GPS e a câmara, além de pequenas variações no nivelamento do berço da aeronave.

De forma a manter a quantidade e configuração dos pontos de verificação constante, foram definidos dois conjuntos de pontos de verificação. Um conjunto de pontos será o mesmo para todos os experimentos (conjunto 1), e o que variará em cada teste será o numero de pontos de apoio. Os pontos retirados da categoria apoio a cada experimento passam a fazer parte de outro conjunto de pontos de verificação (conjunto 2), conforme a Tabela 6. Estas configurações foram definidas de forma a permitir que os valores estimados em cada experimento de fototriangulação possam ser comparados a uma referência comum (conjunto 1 de pontos de verificação).

Tabela 6 - Configurações dos experimentos realizados.

\begin{tabular}{c|c|c}
\hline Experimento & Apoio & Verificação:Conjunto 2 \\
\hline 1 & 8 & 0 \\
\hline 2 & 5 & 3 \\
\hline 3 & 3 & 5 \\
\hline 4 & 1 & 7 \\
\hline 5 & 0 & 8 \\
\hline
\end{tabular}

A Figura 8 mostra a disposição dos pontos de apoio e de verificação para o primeiro experimento. Para este mesmo bloco, foram usados 2268 pontos fotogramétricos coletados de forma automática pelo LPS, e posteriormente refinados ou eliminados de forma manual.

Figura 8 - Disposição dos Pontos de apoio e verificação no bloco de imagens.

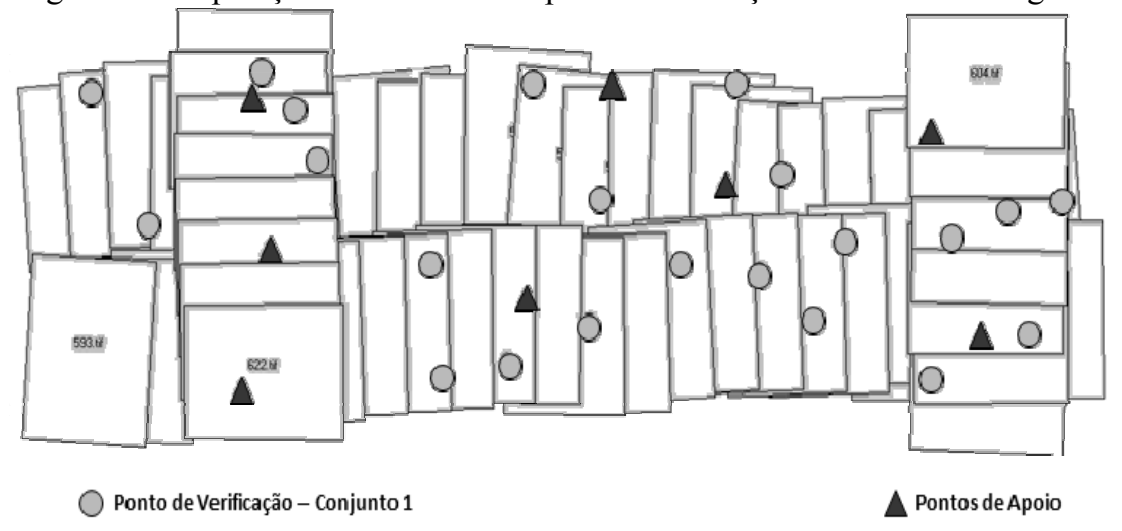

Bol. Ciênc. Geod., sec. Artigos, Curitiba, v. 17, nº 3, p.317-339, jul-set, 2011. 
Os resultados dos processamentos são exibidos nas Figuras 9, 10 e 11.

Figura 9 - Erro Médio Quadrático nos pontos de apoio nos experimentos realizados.

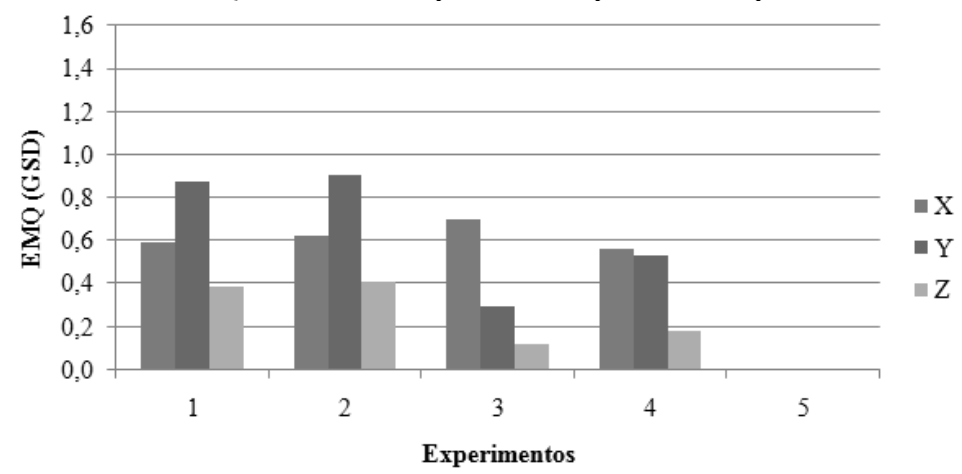

Figura 10 - Erro Médio Quadrático nos pontos de verificação - conjunto 1.

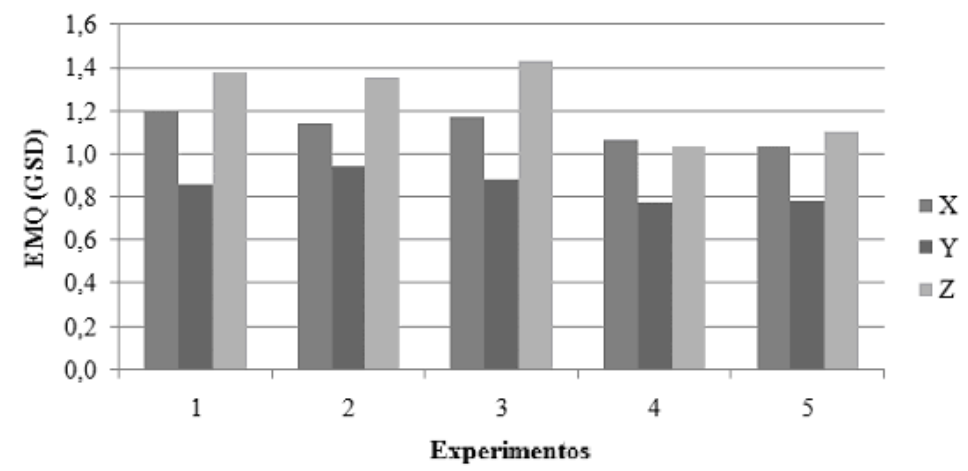

Figura 11 - Erro Médio Quadrático nos pontos de verificação - conjunto 2.

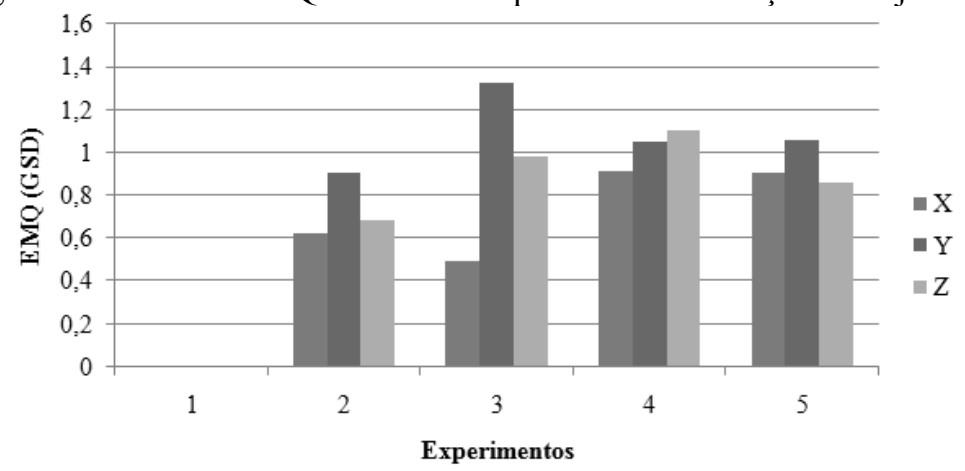

Bol. Ciênc. Geod., sec. Artigos, Curitiba, v. 17, no3, p.317-339, jul-set, 2011. 
Pode-se observar pela Figura 10 (conjunto 1 de pontos de verificação) que, mesmo reduzindo-se o número de pontos de apoio em cada experimento, as discrepâncias mantiveram-se com valores similares. O mesmo pode ser observado na Figura 11.

Observando as Figuras 9, 10 e 11 conjuntamente, pode-se notar que, à medida que são retirados pontos de apoio (que passam a ser usados como pontos de verificação) o EMQ dos pontos do conjunto 1 diminui. Este explicado pelo erro introduzido nas medições dos pontos de apoio na imagem, que foram feitas de forma manual e monoscopicamente, com um erro de medida com magnitude de 1 pixel que é propagado para todo o bloco. No caso das medições dos pontos fotogramétricos, realizadas automaticamente com correlação por mínimos quadrados, o erro é subpixel, e menor do que 1/3 do pixel.

No caso estudado, os resultados mostram que a determinação das coordenadas do CP por georreferenciamento direto (tanto pela técnica 1, quanto pela técnica 2) e o processo automático de medição de pontos por correlação permitem uma exatidão final que não é melhorada com a introdução de mais pontos de apoio.

Pode-se notar que a reamostragem das imagens do bloco de fatos compensou os erros sistemáticos na imagem, como a translação do ponto principal e distorções das lentes da câmara, cujos parâmetros foram estimados na calibração, visto que os parâmetros se comportaram muito bem com todo o bloco, proporcionando os resultados observados.

Mesmo com a redução ou a eliminação total dos pontos de apoio, o EMQ se manteve na casa de 1 GSD $(0,15 \mathrm{~m})$, o que implica que os CPs determinados pela técnica 1 foram estimados de forma satisfatória, permitindo seu uso em aplicações de aquisição de imagens aéreas para mapeamento.

\section{CONCLUSÕES}

A primeira análise foi feita pela comparação dos instantes de disparos registrados pela técnica 1 e 2. Notou-se que a combinação Linux $+\mathrm{NTP}+\mathrm{LinuxPPS}$ proporcionou resultados satisfatórios no sincronismo entre os relógios do GPS e do computador, fornecendo diferenças máximas de 0,00004 s $(40 \mu \mathrm{s})$, quando corrigidos de valores registrados durante as amostragens realizadas pelo NTP, para ajuste do relógio do computador (16,67 minutos de sincronismo).

Este erro no sincronismo entre o receptor GPS e o computador, insere uma discrepância inferior a $0,005 \mathrm{~m}$ nos valores de coordenadas determinadas por interpolação dos CPs em função do tempo, podendo ser desconsideradas nos casos estudados. Esta constatação experimental pode ser destacada como uma das contribuições mais relevantes deste trabalho.

É importante citar que o LinuxPPS em conjunto com o NTP foi usado para ajustar o horário do computador via pulso 1 PPS e mensagens NMEA vindas do 
GPS. Assim, os disparos da câmara foram registrados diretamente no computador já sincronizado com o tempo GPS, usando o pino 1 da porta serial.

Comparações entre as coordenadas dos CPs das duas técnicas proporcionaram discrepâncias menores que $0,5 \mathrm{~m}$ em todo o levantamento, mesmo considerando o uso de um receptor de simples frequência.

É importante destacar que foram feitas as compensações referentes ao vetor que liga a câmara ao centro de fase da antena, proporcionando valores referentes ao CP de cada imagem (Lever Arm).

Para permitir a realização da fototriangulação do bloco, além da calibração da câmara utilizada, considerou-se um sistema local, de maneira a evitar distorções de escalas inseridas por projeções cartográficas, como a UTM. A realização da autocalibração foi feita em um bloco reduzido de imagens, com faixas cruzadas, posições dos CPs com precisões proporcionadas pelo sistema SPAN/CPT - GPS L1/L2 e 9 pontos de apoio.

Como forma de testar a influência dos erros de sincronismo e registro de eventos, 5 experimentos foram realizados considerando o uso dos CPs obtidos pelas técnicas 1 na fototriangulação das imagens adquiridas. Para estes experimentos, consideraram-se fixos os parâmetros da câmara (OI) e as coordenadas dos CPs.

Variou-se o número de pontos de apoio e de verificação, além do uso de dois conjuntos de pontos de verificação: um conjunto com 22 pontos e outro conjunto composto pelos pontos de apoio, que foram reduzidos em cada experimento, até não se fazer uso de pontos de apoio, no experimento 5.

Apesar de se considerar um desvio padrão maior para as posições obtidas com o receptor de simples freqüência $(\sigma=0,20 \mathrm{~m})$, os valores das discrepâncias nos pontos de verificação em todos os experimentos permaneceram muito similares, possibilitando concluir que a técnica 1 foi suficiente para a obtenção das informações de georreferenciamento de imagens digitais, no caso estudado.

A extrapolação destas conclusões para outros blocos de maiores dimensões e com outras configurações depende de validação experimental e está fora do escopo deste trabalho, deixando-se como sugestão para trabalhos futuros.

\section{AGRADECIMENTOS}

Os Autores deste artigo agradecem à CAPES pelo apoio ao projeto, por meio de uma bolsa de mestrado. Agradecem também à empresa Engemap - Engenharia, Mapeamento e Aerolevantamento Ltda., pela cessão de sua aeronave, equipamentos e pessoal, permitindo a execução do voo e coleta de pontos de apoio, bem como toda estrutura para ser possível realização dos experimentos apresentados neste trabalho.

\section{REFERÊNCIAS BIBLIOGRÁFICAS}

ANDRADE, J.B. Fotogrametria SBEE, Curitiba, 1998, 258 p. 
CRAMER, M.; STALLMANN, D.; HAALA, N. Using GPS/Inertial Exterior Orientation Measurements for Photogrammetric Point Determination. In: ISPRS Workshop Com III.1: "Direct Versus Indirect Methods of Sensor Orientation”, 1999, Barcelona, Proceedings of ISPRS Workshop, Barcelona: ISPRS, 1999.

CRAMER, M.; STALLMANN, D.; HAALA, N.. Direct georeferencing using GPS/inertial exterior orientations for photogrammetric applications. International Archives of Photogrammetry and Remote Sensing, v.33, n. B3/1; PART 3, 2000, p.198-205.

EL-SHEIMY, N. The Development of VISAT - A Mobile Survey System for GIS Applications. Tese de Doutorado. (Doctor of philosophy) - Department of Geomatics Engineering, University of Calgary, Calgary, Setembro de 1996

GPLV3. GNU General Public License. Disponível em <http://www.gnu.org/ copyleft/gpl.html $>$. Acesso em: 15 de janeiro de 2009 .

HABIB, A. F.; MORGAN, M. F. Small format digital cameras for mapping applications: Calibration and Stability Analysis. In: Série em Ciências Geodésicas. v. 3, Curitiba, 2003.

JACOBSEN K. System Calibration for Direct and Integrated Sensor Orientation, Theory, Technology and Realities of Inertial/GPS Sensor Orientation, ISPRS WG I/5, Barcelona 2003, on CD ROM, 6 p.

LINUSPPS Disponível em: <http://wiki.enneenne.com/index.php/LinuxPPS support>. Acesso em: 27/06/2011.

MIKHAIL, E. M.; BETHEL, J.S.; McGLONE, J.C. Introduction to Modern Photogrammetry. John Wiley \& Sons, 2001, 479 p.

MILLS, D. L. On the Accuracy and Stability of Clocks Synchronized by the Network Time Protocol in Internet System. University of Delaware, Computer Communication Review, v. 20, n. 1, p. 65-75, 1990.

NTP. Official NTP Documentation, Disponível em: $<$ http://www.eecis.udel.edu $/ \sim$ mills/ntp/html/index.html $>$. Acesso em abril de 2008.

PETRIE, G. Current Developments in Airborne Digital Frame Cameras: As Displayed in the Intergeo 2010 Exhibition. GeoInformatics, v. 13, n. 8, p. 3440, 2010.

REIS, T. T. Estudo e Implementação de Técnicas de Sincronismo de Dispositivos e Georreferenciamento de Imagens Digitais. 2009. Dissertação (Ciências Cartográficas) - Universidade Estadual Paulista Júlio de Mesquita Filho.

RUY, R. S. Desenvolvimento e Validação Geométrica de um Sistema para Mapeamento com Câmaras Digitais de Médio Formato e Georreferenciamento Direto. 2008. 261 f. Tese (Doutorado em Ciências Cartográficas) - Faculdade de Ciências e Tecnologia: Universidade Estadual Paulista, Presidente Prudente.

SEEBER, G. Satellite Geodesy: Foundations, methods, and applications. 2.ed. New York: Walter de Gruyter, 2003. 589p. 
SKALOUD, J. Optimizing Georeferencing of Airborne Survey Systems by INS/DGPS. 1999. Ph.D Thesis. Dept of Geomatics Engineering. The University of Calgary, Calgary.

VISUALGPS, LLC. Disponível em: <http://www.visualgps.net/NMEATIme/ default.htm>. Acesso em: 27/06/2011.

WIS, M.; SAMSÓ, L.; AIGNER, E. COLOMINA I. Present Achievements of Experimental System TAG. The International Archives of Photogrammetry, Remote Sensing and Spatial Information Sciences, vol. 34, 2004.

WOLF, P.R., DEWITT, B.A. Elements of Photogrammetry: with Applications in GIS. 3rd ed. McGRAW-HILL, 2000.

(Recebido em abril de 2011. Aceito em julho de 2011) 